\title{
Applied Paramedic Law and Ethics: Australia and New Zealand
}

\author{
Ruth Townsend \& Morgan Luck \\ Elsevier Australia 2013 \\ Chatswood, Australia \\ ISBN: 9780729541343 (Paperbound) \$AUD 64.94 (RRP including GST)
}

Linda Ross BParamedStud

Affiliation:

Monash University, Department of Community Emergency Health and Paramedic Practice, Frankston, Victoria, Australia

Corresponding Author: Linda.Ross@monash.edu

Teaching the legal and ethical components of paramedic practice is an arduous yet essential task. Paramedics are required to make judgement calls guided by ethical principles and supported by law on a regular basis. This text is both timely and relevant given the increasing litigious climate within which paramedics operate and the current movement to have the paramedic discipline recognised as a profession.

Ruth Townsend has extensive credentials as a nurse, paramedic and lawyer. This expertise coupled with that of her co-author, Morgan Luck, and the numerous contributors, ensures the text delivers a wealth of knowledge and experience to the reader.

This text is 'the first of its kind to bring together legal and ethical concepts specifically for the Australian and New Zealand paramedic profession'. It aims to explore legal and ethical principles and specific regulations relevant to paramedic practice. The authors couple factual content with paramedic specific examples to complement and add context to these often complex issues. This makes it particularly useful for paramedic students with limited in-field experience to draw upon.

The book is organised into fourteen chapters each beginning with specific learning objectives, definitions of key terms employed within the chapter, and ending with review questions. Each chapter also presents case scenarios or situations relevant to the topic, which brings perspective to the content and can be used to evoke discussion and greater understanding. The first chapter introduces ethics, law and professionalism and their importance to paramedics in their daily practice as well as to the advancement of the profession as a whole. The following three chapters deal specifically with ethics. They delve into ethical misunderstandings, theories, governance, and outline a useful ethical decisionmaking model for paramedics. Chapter's five to seven describe aspects of the legal system and how they relate to paramedic practice. Further detailed material exploring the issues of consent, negligence and liability is provided. The next section, chapters eight to thirteen, explore specific legal and ethical issues relevant to paramedic practice including, end of life care, mandatory reporting, mental health, industrial law, record keeping and drug use. Legislation pertaining to these issues is summarised in clear, easy to follow tables covering all states and territories within Australia and New Zealand. The final chapter discusses some current legal and procedural issues relating specifically to the New Zealand context.

My only concern regarding this resource for undergraduate paramedics is the overwhelming nature and complexity of the legal definitions and procedures discussed in depth. This issue could be managed by educators drawing on the resource to support their teaching and by utilising the numerous case studies to explain and discuss issues. The examples outlined in the chapters are a particular strength as they allow complicated subjects to be simplified and contextualised into paramedic specific situations.

The following is an example from chapter two, which could be utilised to discuss ethical and legal considerations surrounding 'Not for Resuscitation' orders. 
Ross, L

DNR Tattoo

A paramedic is called to the scene of a

suspected heart attack. Upon arriving at the

scene it is determined that the patient, an 88-

year-old man, is unconscious and not

breathing.

While preparing to resuscitate the patient, the paramedic discovers the words 'Do not

resuscitate' tattooed on the patient's chest.

Another consideration when purchasing or utilising this text would be currency, as regular rewrites will be necessary to account for legislative changes. On the whole however, I found this text to be a thorough, well-written and useful resource and would recommend it for student paramedics and educators alike. 